\title{
Preliminary Investigation of Carbonation Problem Progress in Concrete buildings of North Cyprus
}

\author{
Salim Idris Malami ${ }^{1, *}$, Pinar Akpinar ${ }^{2}$, and Mustapha Muhammad Lawan ${ }^{1}$ \\ ${ }^{1}$ Department of Civil Engineering, Faculty of Engineering, Kano University of Science and Technology, Wudil, Kano, \\ Nigeria. \\ ${ }^{2}$ Department of Civil Engineering, Faculty of Engineering, Near East University, Nicosia, North Cyprus.
}

\begin{abstract}
Carbonation process is regarded as one of the most critical durability problem in concrete. As a result of carbonation process, the $\mathrm{pH}$ level in concrete is reduced and corrosion of reinforcements initiates, yielding significant damage both in reinforcements and concrete. This study, aimed to investigate experimentally on evaluation performance of existing reinforcedconcrete structures prone to carbonation in North Cyprus. Five inland and five coastal concrete structures of ages varying between 10 and 41 years were selected as the focus of this study. The compressive strength was determined by testing concrete core samples extracted from the selected structures. Same core samples used for determination of carbonation depth, carbonation in the samples was measured by using phenolphthalein indicator test. A contribution to the related literature on carbonation resistance performance of concrete structures under varying exposure conditions of North Cyprus was made for the very first time with the results obtained from this study. Results shows that inland structures have more carbonation depths when compared with structures located in coastal areas. The result also shows that the final carbonation depths observed in the structures are highly depended on the age, initial quality of the concrete as well as the exact local exposure conditions.
\end{abstract}

\section{Introductions}

Carbonation is one of the major problems that may affect the performance of reinforce concrete structures in long-term. Carbonation process involves the reaction of atmospheric carbon dioxide $\left(\mathrm{CO}_{2}\right)$ with calcium hydroxide $\left(\mathrm{Ca}(\mathrm{OH})_{2}\right)$, one of the major cement hydration products, to form calcium carbonate $\left(\mathrm{CaCO}_{3}\right)$. As a result of this reaction the concrete microstructure is altered and the $\mathrm{pH}$ level in the concrete pore solution is decreased. As carbonation progress inwards, this decrease in the $\mathrm{pH}$ can initiate reinforcement corrosion and may yield severe damage in the structures $[1,2]$.

Concrete material's composition, concrete strength and quality, as well as environmental conditions like $\mathrm{CO}_{2}$ content present, relative humidity and temperature are known to affect the extent and the rate of carbonation occurring in structure [2-4].

Being a Mediterranean island, Cyprus experiences high relative humidity and high temperature values throughout the year. The $\mathrm{CO}_{2}$ content in the atmosphere has significantly increased with the developing industrial activities and increasing population especially in the inland areas of the island, which is expected to increase the likelihood of carbonation progress in the existing structures. However, to the best of our knowledge no previous studies had been carried out in Northern Cyprus to report the level of carbonation occurring in the existing reinforced concrete structures. Therefore, this study had the aim to provide experimental information on the carbonation depths as well as the compressive strength of existing structures having ages between 10-41 years that are located both in inland (Nicosia) and coastal (Kyrenia) areas of North Cyprus as shown in figure 1 as location A and B respectively for the very first time.

Using the actual carbonation depths measured in this study a projection was also made for the carbonation depths expected in 50 years lifetime of the structures, with the aim of investigating the necessity of precautions to be takes for the preservation of existing structures under the effect of carbonation. The detailed information

\footnotetext{
* salimmalami@kustwudil.edu.ng
} 
on the experimental procedures, discussion of results obtained, conclusions and the recommendations for future studies are presented in the following sections.

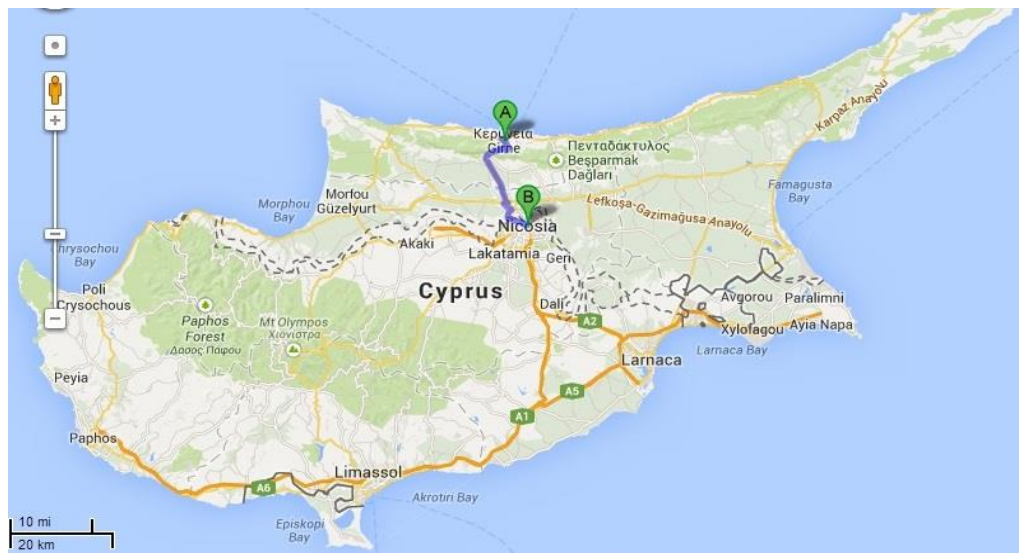

Fig.1. Location of the Surveyed Structures in North Cyprus

\section{Experimental Procedures}

Samples from ten different reinforced concrete structures in North Cyprus were examined in this study; out of which five of them were obtained from Nicosia city (inland area) and the other five from Kyrenia City (coastal area). Information on the age of the surveyed structures was obtained from the owners of the buildings, mainly using the title deeds records. The ages of these selected structures were found out to be varying between 10-41 years

Cylindrical core samples of $65 \mathrm{~mm}$ diameter and $70 \mathrm{~mm}$ height were extracted from the selected elements of the reinforced concrete structures (see figure 2) by the staff of Cyprus Turkish Chamber of Civil Engineers (KTIMO) Laboratory, North Nicosia.

Cores from reinforced concrete structures were extracted according to the procedure proposed in standard method TS-EN 12504-1 [5], which is the Turkish version of EN 12504-1, "Testing Concrete In Structures Part 1: Cored Specimens - Taking, Examining And Testing In Compression", directly adopted by Turkish Standards. Three samples from different locations of each building were extracted for examination. After samples were extracted from existing buildings by the Cyprus Turkish Chamber of Civil Engineering (KTIMO) Laboratory Nicosia, compressive strength of concrete cores was determined and reported by the chamber in accordance with TS-EN 13791 "Assessment of in-situ compressive strength in structures and precast concrete components" [6]. The average for the compressive strength values determined for three samples were reported.

After being tested under compression, the remaining parts of these fractured samples were further studied at the Civil Engineering laboratory of Near East University (N. Cyprus) for the determination of depth of carbonation that had been progressing in the samples throughout the lifetime of the selected structures.

In this study conventional phenolphthalein indicator test was carried out to determine the carbonation depths in the selected structures. Even though this practical test is widely used as the first step to detect presence of carbonation in samples, there is no standard procedure specifying it. There are only advisory documents, such as RILEM Recommendation CPC 18 and Building Research Establishment Digest 405, explaining the test procedure [7]. Following the procedure, a solution of 1 gram phenolphthalein dissolved in $50 \mathrm{ml}$ ethanol and then diluted to $100 \mathrm{ml}$ volume with addition of de-ionized water was prepared. The carbonation depth on the extracted concrete core samples were assessed with the aid of this phenolphthalein indicator solution, which was uniformly sprayed on the inner face of two halves of the fractured cores samples (i.e. after being tested under compression).

The prepared phenolphthalein indicator solution turns to pink color if the $\mathrm{pH}$ of the treated area of concrete or mortar sample is above 9.5. If the treated surface of the samples has a $\mathrm{pH}$ value lower than 9.5, its color remains unchanged, indicating presence of carbonation [8]. Normal concrete pore solution is always saturated with calcium hydroxide, along with potassium and sodium hydroxide, which yield the $\mathrm{pH}$ level to be typically in the values of 13-14. However, concrete samples having a lower $\mathrm{pH}$ as 10-12 might be affected by carbonation to a certain extent, even though pink color would be detected with phenolphthalein test. Therefore, using phenolphthalein indicator test is known to be likely to underestimate the actual depth of carbonation occurred in 
the samples [2]. In any case, with its feasible procedure, this widely used method enables the researchers to gain information on the minimum depth of carbonation occurred, always bearing in mind that the actual depth might be more than that of detected by the test.

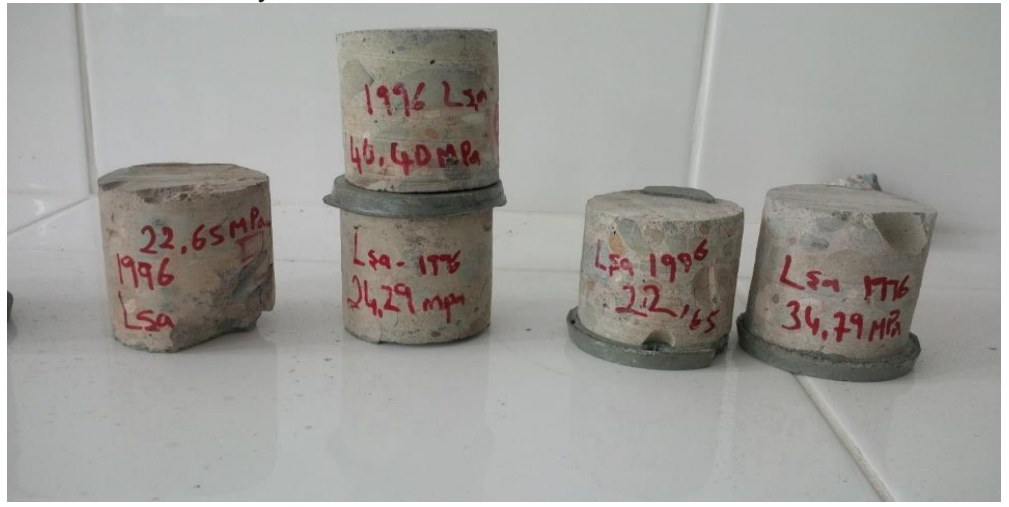

Fig.2. Sample of Drilled Cores from Existing Buildings

\subsection{Measurements and Calculations}

The depths of the uncolored (i.e. carbonated) portion in the samples was measured at three different positions (as $X_{1}, X_{2}$ and $X_{3}$ ) as shown in figure 3 are recorded and their average was reported as the carbonation depth of each halve $\left(\mathrm{d}=\frac{\mathbb{X}_{1+X_{2}+X_{\mathrm{g}}}}{3}\right)$.

Then, the average of the two halves of the core was calculated and recorded as the carbonation depth for one core sample. Finally, the average depths of all cores from the same structure is calculated and reported as shown in Table 1, along with the average compressive strength values provided by the Cyprus Turkish Chamber of Civil Engineers.

Carbonation is a diffusion process, which propagates in to the concrete in accordance with the diffusion laws. Concrete carbonation penetrates in to the concrete depth according to Fick's Law, which suggests that the rate of diffusion in concrete and the distance between concrete surface and reinforcement bars (Concrete cover thickness) have inverse relationship as shown in equation (1) below [9]:

$$
\frac{d_{x}}{d_{t}}=\frac{D_{0}}{x}
$$

Where; $\quad \mathrm{x}$ is the distance from surface of the concrete, $\mathrm{t}$ is the time and $\mathrm{D}_{0}$ is Diffusion rate, which depends on concrete quality. When concrete is carbonated, changes occur in the characteristics pore voids and reduction it base contents result in decrease in $\mathrm{pH}$.

$$
X=B \sqrt{t}
$$

Equation (2) above was obtained after the integration of equation (1) and introducing the B parameter, being equal to $2 \sqrt{D_{0}}$; in which, $\mathbf{B}$ is the carbonation constant that depends on the concrete quality and building exposure conditions in $\mathrm{mm} / \mathrm{year}^{0.5}, \mathbf{d}$ is the measured carbonation depth in $\mathrm{mm}$ and $\mathbf{t}$ is the age of the concrete in years. Further modifications on this relationship are proposed and used by Sim (1994) [10], and also by Haque and Al-Khaiat (1997) [11], and as a result equation (3) was used in their studies for the determination of carbonation depth in concrete:

$$
d=10 B \sqrt{t}
$$

Equation (3) was adopted in this study, in order to predict the future carbonation depths in concrete structures of North Cyprus, where the environmental conditions are favorable for yielding high carbonation rates

The expected carbonation depth of ten reinforced concrete buildings selected for this study at the age of 50 years was determined using equation (3), in order to provide insight on the carbonation-resistance performance of these structures during their designed service lives. In addition to this, the expected time at which these 
buildings would experience a carbonation depth of $25 \mathrm{~mm}$, which is the conventional concrete cover thickness used in buildings in North Cyprus, was also predicted by using the same equation. These results are presented in Table 2, along with the carbonation constant -"B" values that were determined for each building by using the actual measured carbonation depths at current ages of each structure.

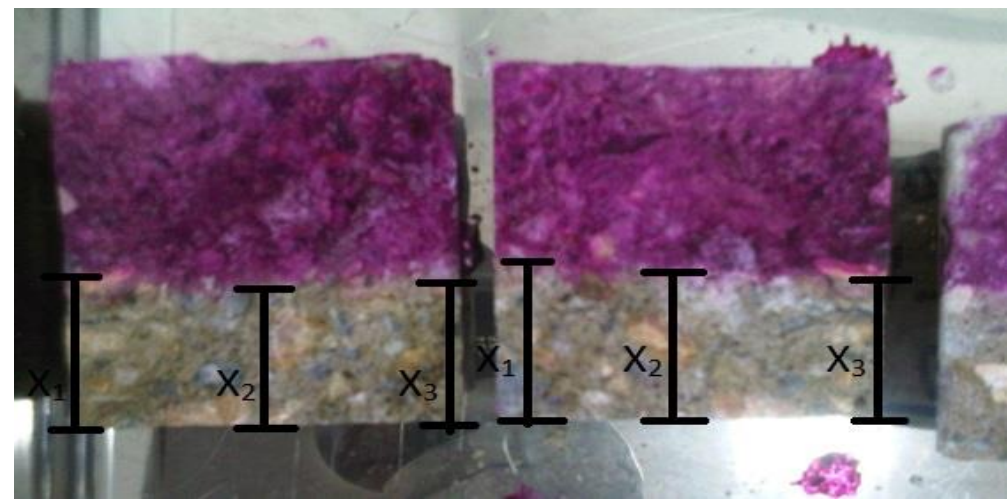

Fig.3. Split Samples Treated with Phenolphthalein Indicator

\section{Results and Discussions}

Table 1 presents the results for the average compressive strength and the average carbonation depth obtained from the core samples extracted from ten different reinforced concrete buildings selected for this study. Please note that the structures 1-5 are located in Nicosia (inland) and structures 6-10 are located in Kyrenia (coastal) cities of North Cyprus.

Table 1. Average Depth of Carbonation and Compressive Strength of the Buildings.

\begin{tabular}{ccccc}
\hline $\begin{array}{c}\text { Str. } \\
\text { No. }\end{array}$ & $\begin{array}{c}\text { Location of the } \\
\text { buildings }\end{array}$ & $\begin{array}{c}\text { Age } \\
\text { (years) }\end{array}$ & $\begin{array}{c}\text { Average } \\
\text { Compressive } \\
\text { Strength (Mpa) }\end{array}$ & $\begin{array}{c}\text { Average } \\
\text { Carbonation } \\
\text { depth (mm) }\end{array}$ \\
\hline 1 & Inland & 18 & 18.93 & 39.0 \\
2 & Inland & 31 & 14.58 & 7.8 \\
3 & Inland & 18 & 29.11 & 32.8 \\
4 & Inland & 18 & 28.72 & 23.9 \\
5 & Inland & 10 & 28.19 & 18.1 \\
6 & Coastal & 21 & 23.51 & 22.7 \\
7 & Coastal & 10 & 26.35 & 10.3 \\
8 & Coastal & 40 & 21.57 & 27.2 \\
9 & Coastal & 41 & 23.85 & 30.4 \\
10 & Coastal & 41 & 22.55 & 37.2 \\
\hline
\end{tabular}

The facts that structures examined in this study located in coastal and inland areas were of different ages and the variations in the exact local exposure conditions of each structure, form a major limitation for defining specific correlations for the age-strength-carbonation depth characteristics. However, since such a survey was carried out for the very first time in North Cyprus, the results obtained in this study are significant for the country, providing insight on the progress of carbonation in existing buildings under varying conditions.

Table 1 and figure 4 demonstrate the average compressive strength values of the structures at the age of testing. Information on the original design strengths of studied structures could not be known clearly. However, all of the structures selected for this study are reported to be residential buildings; and according to information obtained from the interviews made with the staff of Chamber Civil Engineering and experienced engineers working in the concrete manufacture sector, C20 has been used traditionally in the last several decades as the typical grade of concrete used in residential reinforced concrete structures. It observed that two out of the ten structures, structures no-1 and 2 that are both located in inland areas, had the lowest strength values; which were both lower than $20 \mathrm{MPa}$. The rest of the structures of varying ages are observed to have strength values that are higher than $20 \mathrm{MPa}$. While the exact reason of strength variations can not be estimated, it is known that 
carbonation in samples yields the formation of products filling the concrete porosity and therefore, an increase in the compressive strength of the samples can be expected [2].

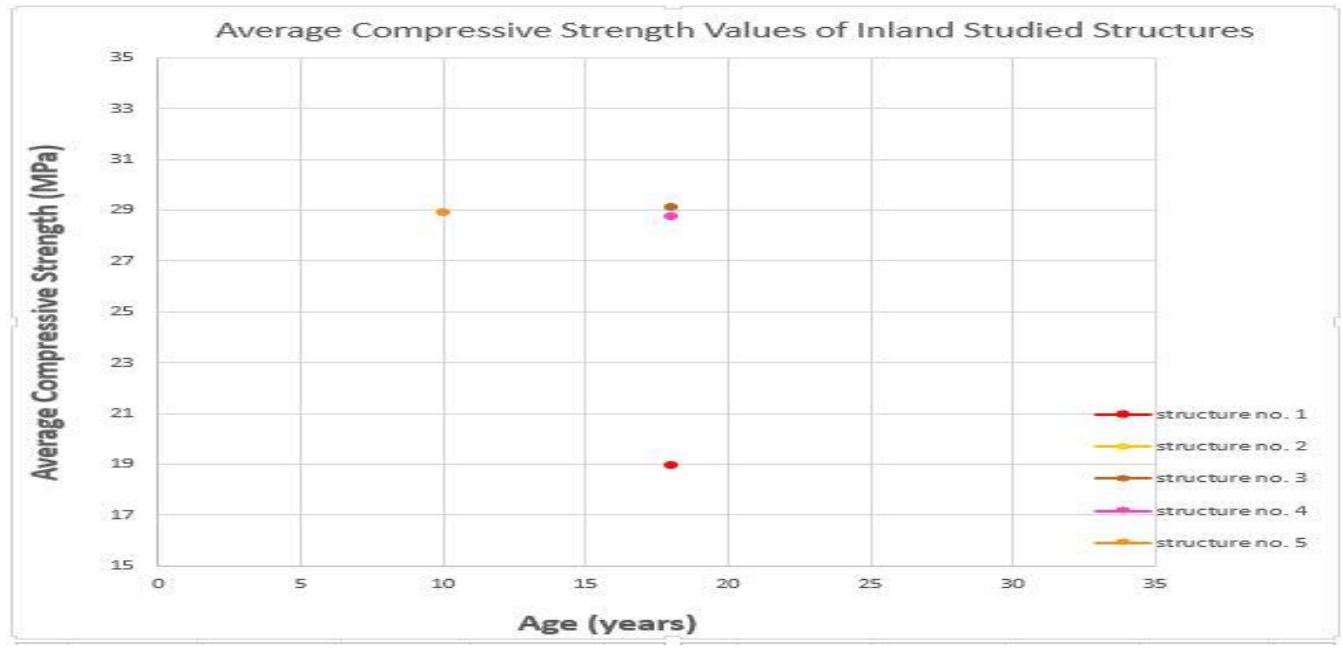

(a) Compressive strength values of inland studied structures

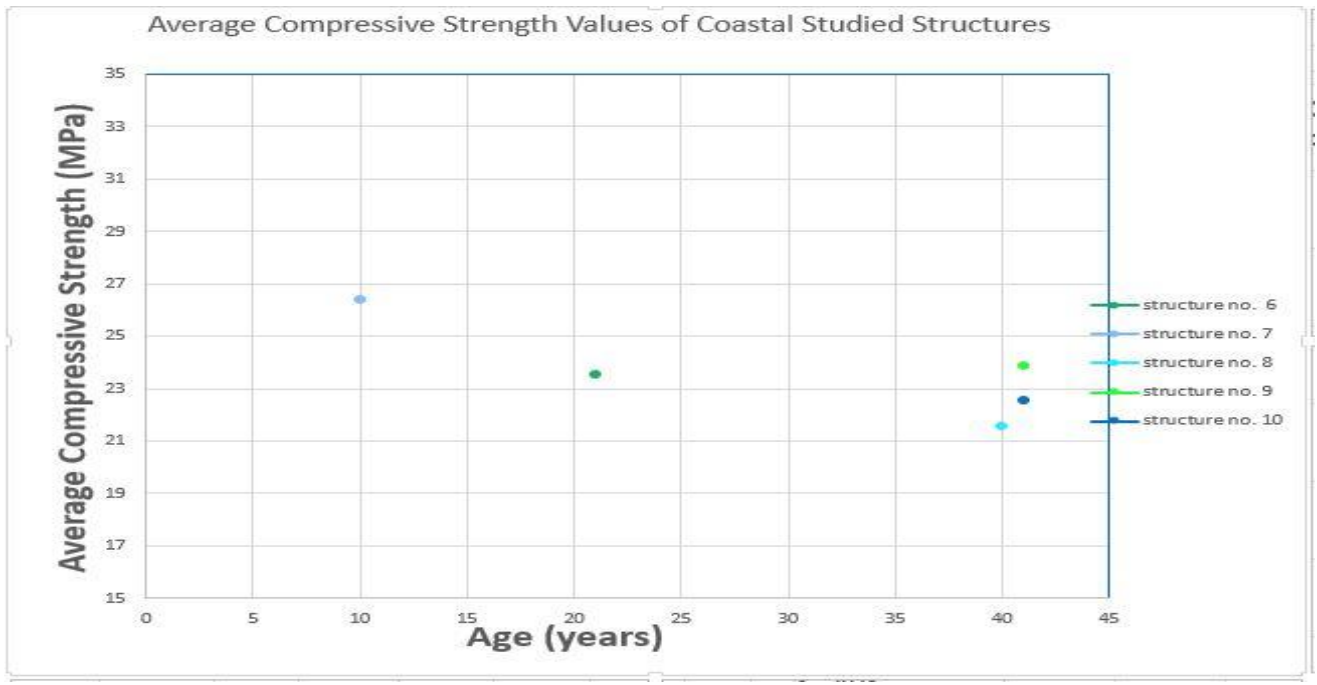

(b) Compressive strength values of coastal studied structures

Fig.4. Average compressive strength values of Inland and Coastal Studied Structures

The carbonation depths determined from extracted concrete cores of the 10 buildings are presented in table 1 and figure 5. When the results of structures no-5 (inland) and no-7 (coastal), both having the same age were compared, it was noted that even the compressive strength values of these structures were similar, their carbonation depths were relatively different. The inland structure (no-5) were observed to have almost $80 \%$ more carbonation depth (see Table1). When structure no-6 (coastal) having the age of 21 years was compared to inland structures no-1, 3 and 4, all being 18 years old (which is the closest age to structure no-6); similarly, inland structures are observed to have higher carbonation depth values than the coastal structure, even though their age was slightly less. Structure no-1 (inland) was observed to have the maximum carbonation depth, as $39 \mathrm{~mm}$, among all structures examined in this study. These observations suggests that generally inland structures in North Cyprus are likely to experience more carbonation occurrence than the structures located in coastal areas. This finding is observed to not to be in accordance with the findings of Haque and Al-Khaiat (1997) [11], which suggested that coastal buildings carbonated more than inland buildings in their studies that was carried 
out in Kuwait. However, this difference in findings is likely to be due to the difference in the exposure conditions of the inland and coastal areas of both countries.

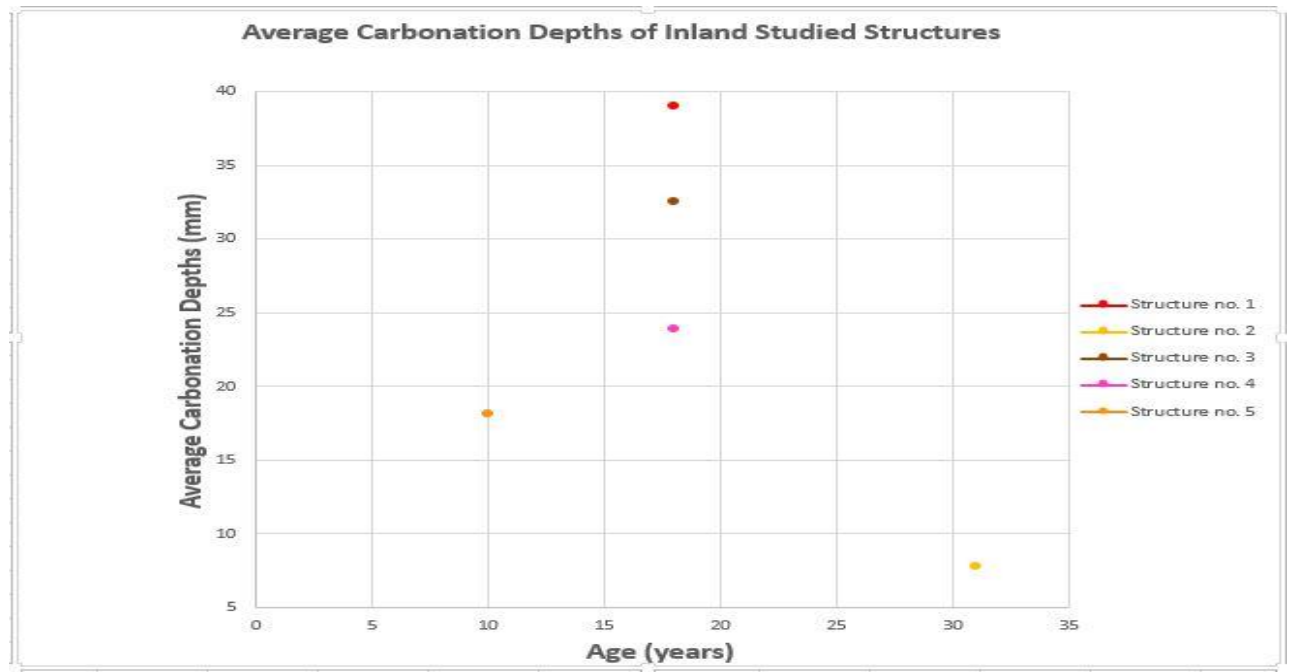

(a) Carbonation depths of inland structures

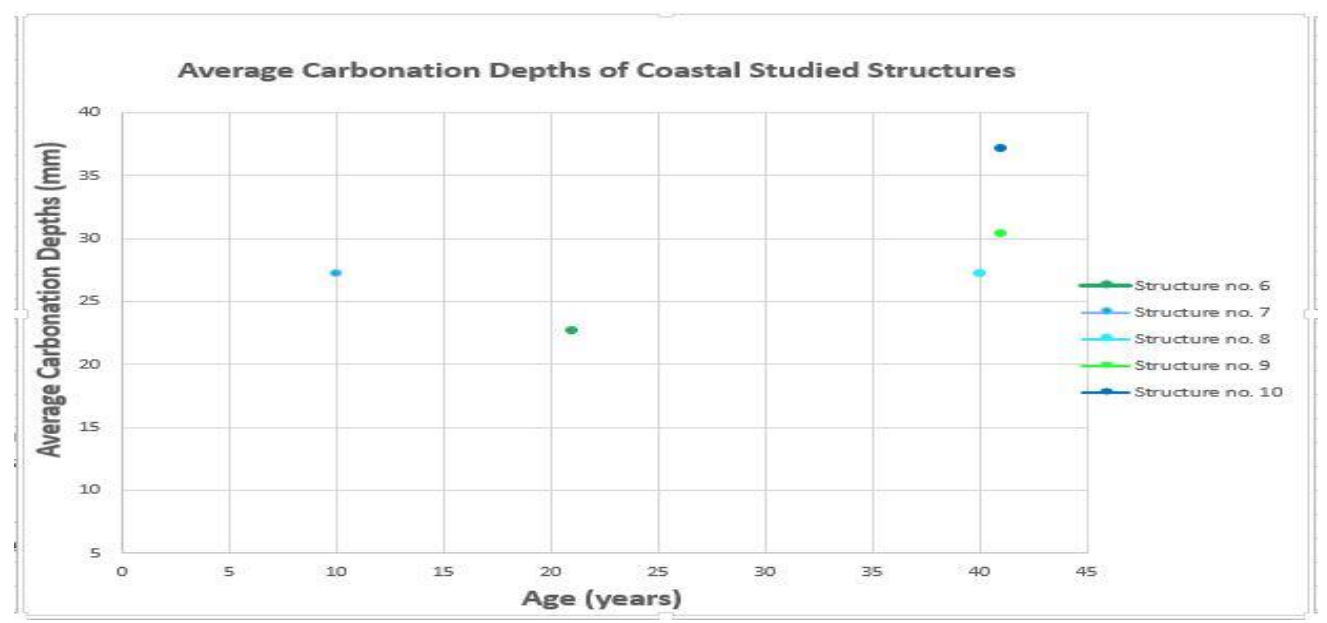

(b) Carbonation depths of coastal structures

Fig. 5. Average carbonation depths of Inland and coastal studied structures

A possible reason for he higher carbonation depths observed in the inland buildings can be due to higher concentrations of $\mathrm{CO}_{2}$ gas affecting the city of Nicosia (inland), since major fraction of the country's industries are located there, and also partly due to the fact that Nicosia has relatively a higher population as it is the capital city of North Cyprus. The average relative humidity in both Nicosia and Kyrenia is within the range of higher rate of carbonation $(50 \%-70 \% \mathrm{RH})$ throughout the year. On the other hand, the difference between the annual average highest and average lowest actual temperatures for inland and coastal areas are reported to be 37.2 $5.2^{\circ} \mathrm{C}$ and $30.8-8.5^{\circ} \mathrm{C}[12]$. Therefore, inland areas are experiencing more temperature difference through out the year.

When inland structures are compared within themselves, like in the case of structures no-1, 3 and 4 , all being 18 years old; it was observed that structure no-1 had the lowest strength and the highest carbonation depth. This finding emphasizes the importance of concrete quality; concrete samples having low strength values are likely to have higher porosity and in such a case, the diffusion of $\mathrm{CO}_{2}$ might be progressing more easily, yielding more depth of carbonation in the samples. On the other hand, one should keep in mind that exact local exposure conditions of each structure have also potential to affect the depth of carbonation observed in the samples. For instance, the case of a structure being exposed to more direct sun or remaining more under shadow, as well as 
any local reason for being exposed to more or less wetting-drying cycles, have the potential to affect the rate of carbonation and the ultimate depth of carbonation observed in the structures. The fact that structures no-3 and 4 , which are both located in inland and having the same age, exhibiting similar strength values but differing carbonation depths may be well due to the reason of having different local exposure conditions. When the carbonation depths of inland structures of different ages are compared, it is observed that the increase in age yielded generally an increased carbonation depth.

When coastal structures were compared within themselves; such as structures no-8 (40 years old), no-9 (41 years old) and no-10 (41 years old), it is observed that their carbonation depths were remarkably varying (e.g. between 27.2-37.2mm), even though their strength values are very similar (e.g. between 21.57-23.85 MPa; see Table 1). This finding may also suggest the importance of the effect of local exposure conditions of each structure on the ultimate depth of carbonation observed in each case. When the carbonation depths of coastal structures of different ages are compared, similar to what is observed in inland structures, the increase in age is observed to yield a higher depth of carbonation.

The carbonation constant "B" values that were calculated with equation (3) defined in previous sections, by using the measured carbonation depths at the current ages that the structures were examined are reported in Table 2. These obtained B values were later used to predict the carbonation depths at 50 years-age and also the time for $25 \mathrm{~mm}$ depth of carbonation, which are both also presented in Table 2. Figure 6 demonstrates the variations of current and predicted carbonation depths in 50 years lifetime for all studied structures

Table 2: Expected Carbonation in 50 years and time to Carbonate $25 \mathrm{~mm}$ Concrete Cover.

\begin{tabular}{lcccccc}
\hline $\begin{array}{l}\text { Str. } \\
\text { No. }\end{array}$ & $\begin{array}{c}\text { Age } \\
\text { (Yrs) }\end{array}$ & $\begin{array}{c}\text { Current } \\
\text { Carbonation } \\
\text { Depth (Mm) }\end{array}$ & $\begin{array}{c}\text { Carbonation } \\
\text { Constant “B” } \\
\left(\mathbf{m m} / \mathbf{y r} \mathbf{r}^{\mathbf{0 . 5}}\right)\end{array}$ & $\begin{array}{c}\text { Expected } \\
\text { carbonation } \\
\text { depths within } \\
\mathbf{2 5} \text { years (mm) }\end{array}$ & $\begin{array}{c}\text { Expected } \\
\text { carbonation } \\
\text { depths within } \\
\mathbf{5 0} \text { years (mm) }\end{array}$ & $\begin{array}{c}\text { Time For } \\
\text { Carbonation } \\
\text { Of 25mm } \\
\text { Cover (Yrs) }\end{array}$ \\
\hline 1 & 18 & 39.0 & 0.92 & 46.05 & 65.05 & 7.4 \\
2 & 31 & 7.8 & 0.14 & 7.00 & 9.90 & 318.9 \\
3 & 18 & 32.8 & 0.77 & 38.50 & 54.45 & 10.5 \\
4 & 18 & 23.9 & 0.56 & 28.00 & 39.60 & 19.9 \\
5 & 10 & 18.1 & 0.57 & 28.50 & 40.31 & 19.2 \\
6 & 21 & 22.7 & 0.50 & 25.00 & 35.46 & 25.0 \\
7 & 10 & 10.3 & 0.33 & 16.50 & 23.33 & 57.4 \\
8 & 40 & 27.2 & 0.43 & 21.50 & 30.41 & 33.8 \\
9 & 41 & 30.4 & 0.47 & 23.50 & 33.23 & 28.29 \\
10 & 41 & 37.2 & 0.58 & 29.00 & 41.01 & 18.58 \\
\hline
\end{tabular}

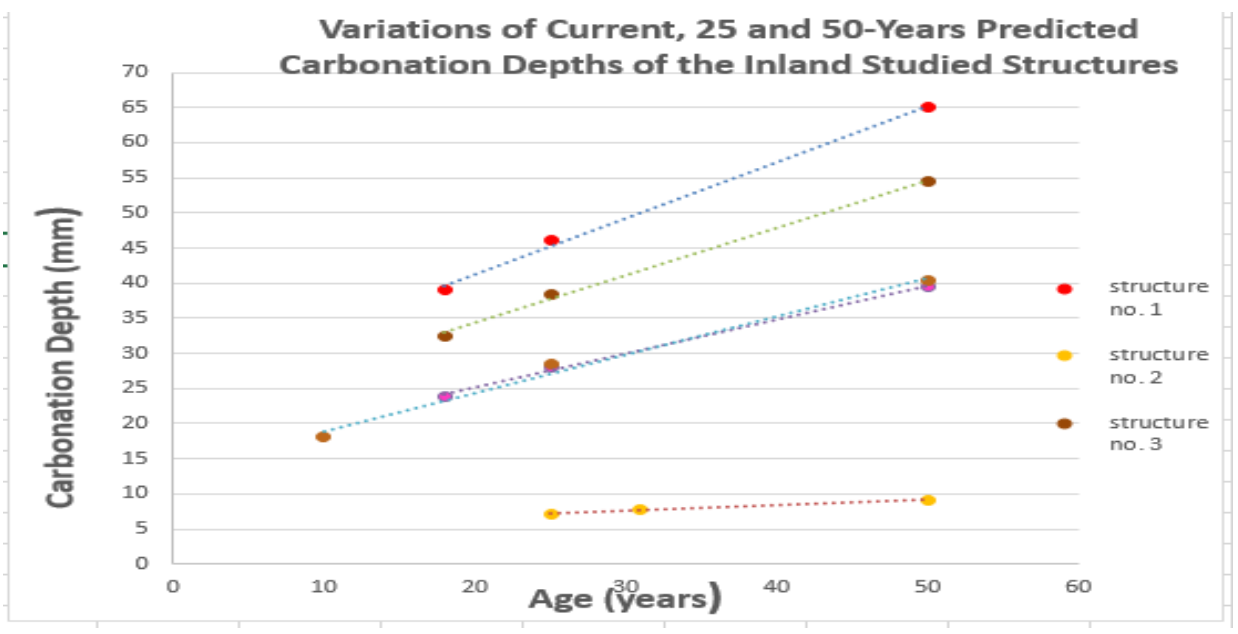

(a) Variations of Predicted Carbonation Depth for Inland Structures. 


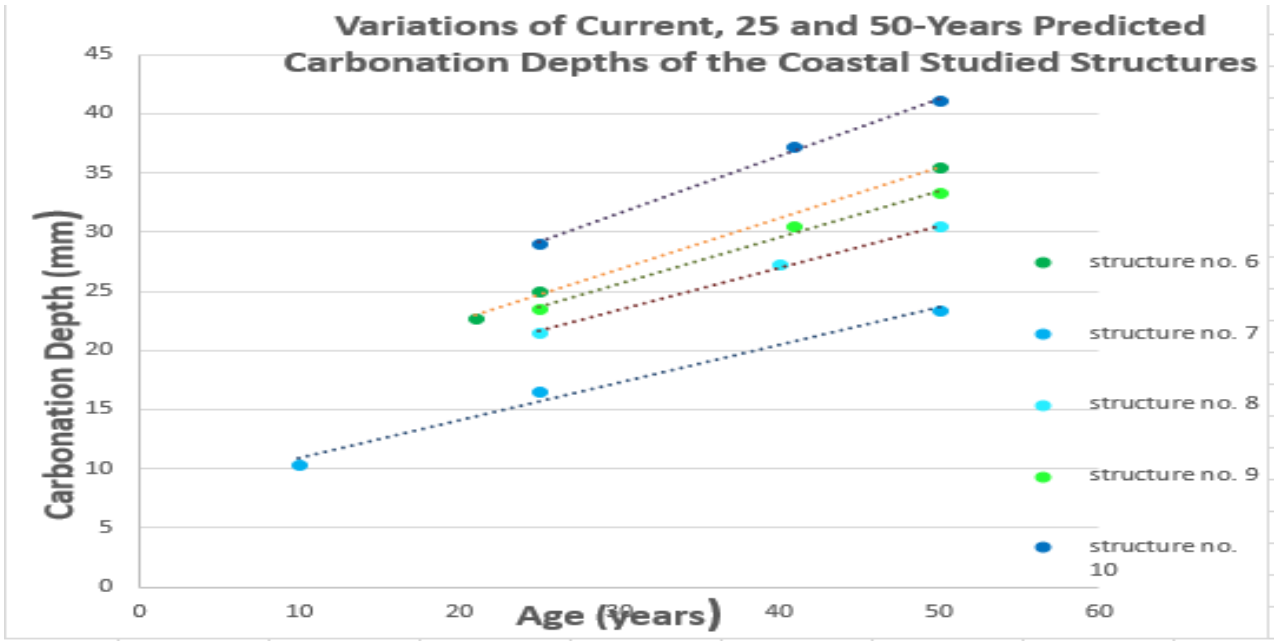

(b) Variations of Predicted Carbonation Depth for Coastal Structures.

Fig.6. Variations of Current, 25 and 50 Years Predicted Carbonation Depth for Inland and Coastal Studied Structures.

For eight out of ten structures, the predicted carbonation depth values for 50 years are observed to be greater than $25 \mathrm{~mm}$, which is the concrete cover thickness conventionally used in North Cyprus. This finding indicates a potential risk of initiation of corrosion and the formation of corrosion-induced damage in structures before the completion of their service lives. In fact, when the predicted time to $25 \mathrm{~mm}$ carbonation depth values reported in Table 2 are studied, it can be observed that five structures (no-1, 3, 8, 9, 10) have already exceeded the limit of $25 \mathrm{~mm}$ carbonation depth, at ages varying between $7.4-33.8$ years. It can be also noted that two structures, no- 4 and 6 , are predicted to have this critical carbonation depth of $25 \mathrm{~mm}$ as soon as in 1.9 years and 4 years respectively, if no precaution for further progress of carbonation is not taken. This finding, together with the observation of previously mentioned structure that have already exceeded $25 \mathrm{~mm}$ carbonation depth limit, indicates that existing structures in North Cyprus are facing carbonation problem in a significant level and adequate precautions should be taken in order to minimize any potential damage occurring due to carbonationinduced reinforcement corrosion in the structures.

\section{Conclusions}

The conclusions drawn from this study are;

- In Northern Cyprus, within the range of studied existing structures, inland buildings were observed to have relatively higher depths of carbonation when compared to coastal buildings.

- Concrete in Northern Cyprus buildings carbonated averagely at a rate of $1.01 \mathrm{~mm}$ per year which is severe and more than expected for normal concrete in hot climate conditions and temperate climate conditions

- Generally, an increase in age of the structure was observed to yield an increased carbonation depth, both in inland and coastal areas.

- The assessment results yielded B values that may be useful in prediction of carbonation depth of reinforced concrete buildings in North Cyprus.

- Results suggest that, beside the main factors such as location and the age, initial quality of the concrete as well as the exact localized exposure conditions of each structure have the potential to affect final carbonation depth observed.

- In severe environment like North Cyprus concrete structures should be built with a concrete of high compressive strength, having a higher density.

- The results obtained on the current carbonation depths of the structures and the predictions made for the expected carbonation progress within their service, indicate that exposure conditions of North Cyprus yield significant levels of carbonation in the reinforced concrete structures. Eight out of ten studied structures were predicted to experience carbonation depths beyond the conventional $25 \mathrm{~mm}$ concrete cover thickness within their designed lifetimes. Therefore, the initiation of reinforcement corrosion is observed to be likely in these structures and taking adequate precautions for minimizing further deteriorations in these existing structures should be considered. 
The authors would like to acknowledge the Cyprus Turkish Chamber of Civil Engineers Laboratory, for their collaboration in providing samples used in this study. The authors would also like to thank to Near East University for providing laboratory staff and facilities for the carrying out of carbonation depth measurements for this study.

Also Kano University of Science and Technology, Wudil.

\section{References}

1. S. K. Roy, K. B. Poh, \& D. O.Northwood, Durability of concrete-accelerated carbonation and weathering studies. Building and Environment, 34, 5, 597-606. (1999)

2. A.M. Neville, Properties of Concrete, fourth ed., Harlow: Prentice Hall, (2005)

3. R. K. Dhir, P.C. Hewlett, Y. N. Chan, Near-surface characteristics of concrete: prediction of carbonation resistance, Magazine of Concrete Research, 41, 148 137-143 (1989)

4. S. Varjonen, Accelerated carbonated concrete as corrosion environment. Nordic Concrete ResearchPublications, 31, 1 (2004)

5. EN 12504-1, Testing Concrete In Structures Part 1: Cored Specimens - Taking, Examining And Testing In Compression, (2009)

6. EN 13791, Assessment of in-situ compressive strength in structures and precast concrete components, (2007)

7. A. M. Neville, Concrete: Neville's Insights and Issues, Thomas Telford, (2006)

8. Y. F. Houst, F. H. Wittmann, Depth profiles of carbonates formed during natural carbonation. Cement and Concrete Research, 32, 12, 1923-1930 (2002)

9. M. El-Reedy, Steel-Reinforcement concrete structure: Assessment and Repair of Corrosion, (2010)

10. Sims, The assessment of concrete for carbonation, Concrete, 28, 33-38 (1994).

11. 11. M. N. Haque, H. Al-Khaiat, Carbonation of concrete structures in hot dry coastal regions, Cement and Concrete Composites, 19, 2, 123-129 (1997)

12. Information on:http://www.moa.gov.cy/moa/MS/MS.nsf/DMLclimet_reports_en/DMLclimet_reports_en? OpenDocument $\&$ Start $=1 \&$ Count $=1000 \&$ Expand $=1$

13. Effective Cost Analysis for Repairing of Corrosion Damaged Reinforced Concrete Structures, Department of Trade and Industry,http://projects.bre.co.uk/rebarcorrosioncost, September 3, (2015)

14. K. R., Larsen, Corrosion Effects on the Durability of Reinforced Concrete Structures, MP Materials Performance,

http://www.materialsperformance.com/articles/material-selectiondesign/2015/12/corrosion-effects-on-the-durability-of-reinforced-concrete-structures September 30, (2015). 